\title{
Knowledge, attitudes, and practices related to adverse drug reaction reporting by healthcare professionals in a tertiary hospital in Malaysia
}

\author{
Ismail Burud ${ }^{1}$, Aqil M. Daher ${ }^{2 *}$, Hwa Biing Din ${ }^{1}$, Puneet Agarwal ${ }^{1}$, Jasiah Zakaria ${ }^{3}$, Renu Agarwal ${ }^{4}$ \\ ${ }^{1}$ Department of Surgery, International Medical University, Clinical campus, Seremban ,70300, Negeri Sembilan, Malaysia. \\ ${ }^{2}$ Department of community Medicine, International Medical University, Bukit Jalil, 57000, Kuala Lumpur, Malaysia. \\ ${ }^{3}$ Department of Surgery, Hospital Tuanku Jaafar, Seremban, 70300, Ministry of Health, Malaysia. \\ ${ }^{4}$ Department of Pharmacology and Therapeutics, International Medical University, Bukit Jalil, 57000, Kuala Lumpur, Malaysia.
}

\begin{tabular}{|c|c|}
\hline ARTICLE INFO & ABSTRACT \\
\hline $\begin{array}{l}\text { Received on: } 07 / 05 / 2021 \\
\text { Accepted on: 09/07/2021 } \\
\text { Available online: } 03 / 10 / 2021\end{array}$ & $\begin{array}{l}\text { Adverse drug reactions (ADR) are a cause of public health concern globally. Voluntary ADR reporting is the basis } \\
\text { of pharmacovigilance program in several countries. However, underreporting of ADRs is widely known among } \\
\text { various World Health Organization member countries, including Malaysia. Hence, this study aimed to assess the } \\
\text { knowledge, attitudes, and practices (KAP) regarding ADR reporting among healthcare professionals in a tertiary }\end{array}$ \\
\hline $\begin{array}{l}\text { Key words: } \\
\text { Adverse drug reaction, } \\
\text { reporting, knowledge, } \\
\text { attitudes, practices. }\end{array}$ & $\begin{array}{l}\text { hospital in Malaysia. A cross-sectional study was conducted using a self-administered questionnaire, which consisted } \\
\text { of } 40 \text { items to assess the KAP regarding ADR reporting. The participants were specialists, medical officers, house } \\
\text { officers, and nurses working at Hospital Tuanku Ja'afar, Seremban, Malaysia. Among the respondents, } 56.9 \% \text { of the } \\
\text { participants had satisfactory knowledge; however, desirable practices were noted among } 37.8 \% \text { of the participants. } \\
\text { Approximately one-fifth of them were found to have attitudinal barriers toward the reporting process, whereas } 40.71 \% \\
\text { showed desirable attitudes toward the motivators for ADR reporting. It was also observed that professionals with } \\
\text { greater knowledge have lesser negative attitudes and greater satisfactory practices, whereas those with greater positive } \\
\text { attitudes have greater satisfactory practices. In conclusion, the healthcare professionals working at a tertiary healthcare } \\
\text { center in Malaysia had satisfactory knowledge but showed poor practices due to perceived barriers toward ADR } \\
\text { reporting processes. }\end{array}$ \\
\hline
\end{tabular}

\section{INTRODUCTION}

Adverse drug reactions (ADRs) are the major cause of public health concern globally as they increase morbidity, mortality, and healthcare cost. An ADR is defined as any response to a drug that is noxious, unintended, and occurs at doses used in humans for diagnosis, prophylaxis, therapy of disease, or modification of physiological functions (World Health Organization, 2020). It is also defined as an appreciably harmful or unpleasant reaction, resulting from an intervention related to the use of a medicinal product that predicts hazard from future administration and

\footnotetext{
*Corresponding Author

Aqil M. Daher, Department of community Medicine, International Medical University, Bukit Jalil, 57000, Kuala Lumpur, Malaysia. E-mail: aqil702001@yahoo.com
}

warrants prevention or specific treatment, alteration of the dosage regimen, or withdrawal of the product (Aronson \& Ferner, 2005)

The ADR-related public health and safety concerns are attributed not only to the fact that ADRs can be life-threatening but also to the fact that they may also cause disability, prolongation of hospital admission, and visits to the emergency department. Studies have shown that ADRs account for $4.2 \%-30 \%$ of hospital admissions in the United States and Canada, $5.7 \%-18.8 \%$ in Australia, and $2.5 \%-10.6 \%$ of admissions in Europe (Howard et al., 2007; Sultana et al., 2013). In Malaysia, 29,983 cases of ADR were reported in 2019 and these numbers were higher by 88\% compared to those reported in 2017 (National Pharmaceutical Regulatory Agency, 2020). This increase may have resulted from increased awareness among healthcare professionals to report ADRs. In most countries, including Malaysia, ADR reporting relies on spontaneous and voluntary reporting by healthcare professionals to national regulatory authorities. In Malaysia, 
the monitoring of the safety profiles of drugs is regulated by the Malaysian Adverse Drug Reactions Advisory Committee under the Drug Control Authority (Sultana et al., 2013). Since Malaysia is a member country, the data are sent to World Health Organization (WHO) Collaborating Center for Drug Safety Program in Uppsala, Sweden, for further evaluation and inclusion in its ADR database.

Despite the existence of a National Pharmacovigilance Program in WHO member countries, underreporting of ADRs has commonly been observed, and in some countries, it may exceed 90\% (Hazell \& Shakir, 2006; Wise et al., 2009). Significant underreporting of ADRs by private practitioners and community pharmacists was reported in Malaysia (Agarwal et al., 2013; Elkalmi et al., 2011). ADR underreporting was also reported by doctors at one of the university hospitals in Malaysia (Aziz et al., 2007). Hence, it is important to determine the causes of underreporting of ADRs. Tertiary healthcare centers in Malaysia have greater access to all relevant information and facilities; however, the knowledge, attitudes, and practices (KAP) toward ADR reporting among healthcare professionals at these centers remain largely unknown. Therefore, we carried out a crosssectional survey among healthcare professionals in a tertiary hospital to assess the KAP toward ADR reporting and identify barriers and motivators toward ADR reporting.

\section{MATERIALS AND METHODS}

\section{Study design and study population}

A total of 370 subjects who met the inclusion and exclusion criteria were recruited based on convenience sampling.

\section{Inclusion and exclusion criteria}

The healthcare professionals included in this study were specialists, medical officers, housemen, and nurses working in Hospital Tuanku Ja'afar Seremban, Malaysia. Participants were required to sign the informed consent.

Healthcare professionals who are solely employed for administrative duties, pharmacists, and those undergoing prequalification training were excluded.

\section{Data collection tool}

The study tool was a self-administered validated questionnaire adapted from a previous study (Agarwal et al., 2013). The questionnaire consisted of two parts: Part I required participants to provide the demographic details, whereas Part II consisted of a total of 40 items to assess the KAP toward ADR reporting. There were 11 items for assessment of knowledge, 7 items for practices, and 22 items for attitudes. The 22 attituderelated items included 11 items each to assess attitudes toward the reporting process and reporting card and 5 items indicated motivators for reporting.

Questions addressing knowledge and practices scored either 0 or 1 . Attitude-related questions were marked on a scale of $1-4$. The sum of scores for individual questions in each domain indicated the total domain score. A total domain score of $70 \%$ or above was categorized as satisfactory, whereas a total domain score of less than $70 \%$ was considered unsatisfactory (Agarwal et al., 2013; Daher and Amin, 2010).

\section{Data collection}

Selected participants were approached in person and the objectives, methodology, and implications of the study were explained to them. Participants were provided with the study information sheet and consent form. Those who agreed to participate in the study were given the questionnaire and were requested to complete it in the same sitting.

\section{Sample size}

The sample size was calculated using the power and sample size v3.2 program. The calculation was based on estimating an odds ratio of 2.5 between two groups of comparison (Agarwal et al., 2013). Hence, the study aimed to detect a difference of 2.5 odds ratio with the precision of 0.05 and power of 0.8 . The minimal expected proportion of unsatisfactory knowledge, attitude, and practice was set at 0.44 . The required sample size was 308 with a distribution of 77 in each of the four groups of participants. The final sample size was 370 after adjusting for $20 \%$ nonresponders.

\section{Ethical approval}

The study was approved by the Institutional Ethics Committee and was included in National Medical Research Registry (NMRR 20-1802-55208).

\section{Data analysis}

Data were analyzed using Statistical Package for the Social Sciences version 24.0. Frequency and percentage were used to describe the categorical variables. Numerical variables are described as mean \pm standard deviation. Chi-square test was used to ascertain the association between socio-demographic characteristics and KAP. Binary logistic regression was applied to identify factors associated with KAP.

\section{RESULTS}

A total of 370 questionnaires were distributed and 339 participants returned the completed questionnaire, yielding a response rate of $91.6 \%$. The mean age of the participants was 33.4 (SD: 9.3) years. The average number of patients given consultation and the average number of prescriptions written by participants per day were 16.9 (SD: 6.9) and 14.7 (SD: 6.9), respectively. Participating healthcare professionals had a mean experience of 8.5 years (SD: 8.4 ) in their field of practice. Among the respondents, 214 participants were female $(63.13 \%)$ and 125 participants were male $(36.87 \%)$. Those from the surgical specialty accounted for $46.02 \%$, whereas the remaining were from medical and other specialties. Among the respondents, 28.02\% were medical officers, $23.01 \%$ were house officers, $23.3 \%$ were specialists, and the remaining were nurses.

\section{Knowledge of healthcare professionals regarding ADR and its reporting}

Majority of the participants correctly responded that all suspected reactions to established drugs should be reported $(95.58 \%)$ and all serious reactions to old and new products should be reported $(83.19 \%)$. Majority of the participants $(79.35 \%)$ correctly responded that all suspected reactions to new products should be reported, while $38.64 \%$ of them wrongly answered that 
only serious reactions should be reported. Moreover, nearly half (44.25\%) of the participants wrongly answered that only proven reactions should be reported.

Most participants $(95.28 \%)$ answered correctly that ADR reporting helps to identify unrecognized ADRs and the predisposing factors. Similarly, majority of the participants also correctly responded that ADR reporting helps to characterize ADRs (89.97\%) and measures the ADR incidence $(85.55 \%)$. However, very few respondents $(9.14 \%)$ answered correctly that ADR reporting helps in comparing drug toxicity in similar therapeutic classes and it does not help to identify safe drugs $(5.6 \%)$ (Table 1). Overall, more than half of the respondents $(56.9 \%)$ had a satisfactory level of knowledge.

\section{Practices of healthcare professionals regarding ADR and its reporting}

Three-fourth of the respondents (75.81\%) answered that they will report serious ADRs and up to $65.78 \%$ of them said that the ADR reporting would be carried out if the reaction is unusual. More than half of the respondents (53.69\%) said that they will report an ADR only if the reaction is new to a product or if they are confident that the reaction is an adverse reaction
(51.92\%). Additionally, $44.84 \%$ of the participants responded that they would report if they have observed a similar reaction to the drug class. Although more than half of the participants (69.91\%) responded that they have reported an ADR to a national reporting agency or pharmaceutical company, up to $71.98 \%$ responded that they did not report a suspected ADR. Overall, more than half of the respondents $(62.2 \%)$ showed undesirable practices (Table 2$)$.

\section{Attitudes of healthcare professionals toward the ADR reporting process and reporting card}

Among the participants, three-fourth (78.2\%) responded that they were unaware of the address of the reporting agency, $77 \%$ of them did not know the relevant phone numbers, and $44.8 \%$ were not sure about the availability of ADR reporting cards. More than half of the participants $(64.6 \%)$ agreed that there are clear guidelines for ADR reporting and $59.6 \%$ of them said that there is disciplinary action for nonreporting. More than half (55.8\%) were worried about legal liabilities and $49.3 \%$ of them said that ADR reporting will jeopardize patient confidentiality. Less than half of the respondents $(34.5 \%)$ said that they were too busy to report ADRs and up to $21.5 \%$ of them felt that they will appear foolish by ADR reporting. Only $18.3 \%$ of the participants said that they are

Table 1. Participants' responses showing their knowledge about the type of ADR to be reported and the purpose of ADR reporting.

\begin{tabular}{lcc}
\hline Queue & Incorrect response & Correct response \\
\cline { 2 - 3 } & $\boldsymbol{n} \mathbf{( \% )}$ & $\boldsymbol{n} \mathbf{( \% )}$ \\
\hline Regarding the type of ADR to be reported & $15(4.42)$ & $324(95.58)$ \\
All suspected reactions to established drugs should be reported & $57(16.81)$ & $282(83.19)$ \\
All serious reactions to old and new products should be reported & $70(20.65)$ & $269(79.35)$ \\
All suspected reactions to new products should be reported & $131(38.64)$ & $208(61.36)$ \\
Regarding type of ADR to be reported, only serious reactions to new products should be reported & $150(44.25)$ & $189(55.75)$ \\
Regarding type of ADR to be reported, only proven reactions should be reported & $16(4.72)$ & $323(95.28)$ \\
The purpose of the national ADR reporting scheme in Malaysia is to & $16(4.72)$ & $323(95.28)$ \\
Identify previously unrecognized ADRs & $34(10.03)$ & $305(89.97)$ \\
Recognize factors predisposing to ADRs & $49(14.45)$ & $290(85.55)$ \\
Characterize ADRs & $308(90.86)$ & $320(94.40)$ \\
Measure the incidence of ADRs & & $31(9.14)$ \\
Enable toxicity of drugs in similar therapeutic classes to be compared & & $19(5.6)$ \\
Identify safe drugs &
\end{tabular}

Table 2. Participants' responses showing their practices toward ADR reporting.

\begin{tabular}{|c|c|c|}
\hline \multirow{2}{*}{ Queue } & Undesirable & Desirable \\
\hline & $n(\%)$ & $n(\%)$ \\
\hline \multicolumn{3}{|l|}{ I will report an ADR, only if } \\
\hline The reaction is serious & $82(24.19)$ & $257(75.81)$ \\
\hline The reaction is unusual & $116(34.22)$ & $223(65.78)$ \\
\hline I have observed similar reactions to the drug class before & $187(55.16)$ & $152(44.84)$ \\
\hline The reaction is to a new product & $157(46.31)$ & $182(53.69)$ \\
\hline I am confident that the reaction is an adverse reaction to the drug & $163(48.08)$ & $176(51.92)$ \\
\hline \multicolumn{3}{|l|}{ I have } \\
\hline Sent an adverse drug reaction report to the national reporting agency or a pharmaceutical company & $102(30.09)$ & $237(69.91)$ \\
\hline Suspected an ADR but did not report it & $244(71.98)$ & $95(28.02)$ \\
\hline
\end{tabular}


trained about the process of ADR reporting. Nearly half of them (46.8\%) wish to publish a case series rather than reporting ADR (Table 3). Overall, nearly one-fifth of the respondents (19.76\%) had perceived attitude barriers and $80.24 \%$ had an acceptable attitude toward the ADR reporting process.

Notably, most of the respondents believed that ADR reporting would trigger further investigation $(77.3 \%)$ or would hold them responsible for causing harm to the patient $(70.2 \%)$. Among all (31.3\%) believed that ADR reporting would put their carrier at risk. Participants also responded that it was timeconsuming to report ADR (55.2\%) and they cannot find the ADR reporting card (41\%). They had difficulty filling up the reporting card $(29.8 \%)$ and said that there was an inadequate space to fill up (31.4\%). Among the respondents, $42.5 \%$ did not wish to include their details and $26 \%$ of them wished not to include patient's details in the ADR reporting card. Only 63 respondents (18.6\%) agreed that reporting an ADR does not contribute to medical knowledge (Table 3 ). Overall, around $10.62 \%$ of the respondents had perceived attitude barriers and $89.38 \%$ had an acceptable attitude toward the reporting card.

Regarding the motivators for ADR reporting, most of the participants $(91.7 \%)$ agreed that in-service training is required and $87 \%$ of them said that the hospital administration should constantly track ADR reports made by healthcare personnel. The majority believed that serious ADRs are already documented when a drug is marketed $(85.6 \%)$, yet they have a responsibility to report ADRs (88.8\%). Only 93 respondents $(27.4 \%)$ expected to be financially reimbursed for ADR reporting (Table 3). Overall, less than half of the participants $(40.71 \%)$ had positive attitudes toward ADR reporting.

\section{Association of knowledge, practices, and attitudes with the socio-demographic characteristics of participants}

The analysis of the association between knowledge and socio-demographic characteristics showed that female participants possess greater satisfactory knowledge compared to

Table 3. Participants' responses showing their attitude and belief toward ADR reporting.

\begin{tabular}{|c|c|c|}
\hline \multirow{2}{*}{ Queue } & Strongly disagree - disagree & Strongly agree - agree \\
\hline & $n(\%)$ & $n(\%)$ \\
\hline \multicolumn{3}{|l|}{ Regarding ADR reporting process } \\
\hline I do not know the address of the agency to which I should report & $74(21.8)$ & $265(78.2)$ \\
\hline I do not know the relevant phone numbers & $78(23)$ & $261(77)$ \\
\hline There are clear guidelines for ADRs reporting in the hospital & $120(35.4)$ & $219(64.6)$ \\
\hline There is disciplinary action for nonreporting & $137(40.4)$ & $202(59.6)$ \\
\hline I am worried about legal liabilities & $150(44.3)$ & $189(55.8)$ \\
\hline Patient's confidentiality is jeopardized during ADR reporting & $172(50.7)$ & $167(49.3)$ \\
\hline I wish to publish a personal series of cases rather than reporting ADRs & $180(53.3)$ & $158(46.8)$ \\
\hline I do not know about the availability of ADR reporting card & $187(55.2)$ & $152(44.8)$ \\
\hline I am too busy to report & $222(65.5)$ & $117(34.5)$ \\
\hline I feel I will appear foolish & $266(78.5)$ & $73(21.5)$ \\
\hline I am trained on the process of reporting ADR & $277(81.7)$ & $62(18.3)$ \\
\hline \multicolumn{3}{|l|}{ Regarding ADR reporting card (blue card) } \\
\hline ADRs may trigger further investigations & $77(22.7)$ & $262(77.3)$ \\
\hline Filling this card will hold me responsible for ADR-related harm to the patient & $101(29.8)$ & $238(70.2)$ \\
\hline It takes too much time to report ADRs & $152(44.8)$ & $187(55.2)$ \\
\hline It requires stating my identity, which I do not wish to provide. & $195(57.2)$ & $144(42.5)$ \\
\hline The card is not available & $200(59)$ & $139(41)$ \\
\hline The space provided to describe the $\mathrm{ADR}$ is inadequate. & $232(68.6)$ & $106(31.4)$ \\
\hline Reporting ADRs puts my career at risk & $233(68.7)$ & $106(31.3)$ \\
\hline It is too difficult to fill up & $238(70.2)$ & $101(29.8)$ \\
\hline It is nearly impossible to determine if a drug is responsible for a particular adverse event & $243(71.7)$ & $96(28.3)$ \\
\hline It requires stating patient's identity, which I do not wish to provide & $251(74)$ & $88(26)$ \\
\hline Reporting of one case of ADR does not contribute to medical knowledge & $276(81.4)$ & $63(18.6)$ \\
\hline \multicolumn{3}{|l|}{ I believe that } \\
\hline In-service training would facilitate/improve/increase ADR reporting & $28(8.3)$ & $311(91.7)$ \\
\hline I have a professional obligation to report ADRs & $38(11.2)$ & $301(88.8)$ \\
\hline Hospital administration should track the ADR reporting by health professionals & $44(13)$ & $295(87)$ \\
\hline Really serious ADR are well documented by the time a drug is marketed & $49(14.5)$ & $290(85.6)$ \\
\hline I should be financially reimbursed for providing the reports of ADRs & $246(72.6)$ & $93(27.4)$ \\
\hline
\end{tabular}


Table 4. Knowledge and practices toward ADR reporting in relation to socio-demographic factors.

\begin{tabular}{|c|c|c|c|c|c|c|c|}
\hline & & \multicolumn{3}{|c|}{ Knowledge } & \multicolumn{3}{|c|}{ Practices } \\
\hline & & Unsatisfactory & Satisfactory & $p$ & Unsatisfactory & Satisfactory & $p$ \\
\hline & & $n(\%)$ & $n(\%)$ & & $n(\%)$ & $n(\%)$ & \\
\hline \multirow[t]{2}{*}{ Age } & $<50$ & $131(41.99)$ & $181(58.01)$ & 0.929 & $188(60.26)$ & $124(39.74)$ & 0.991 \\
\hline & $50+$ & $2(40.00)$ & $3(60.00)$ & & $3(60.00)$ & $2(40.00)$ & \\
\hline \multirow[t]{2}{*}{ Gender } & Male & $69(55.20)$ & $56(44.80)$ & 0.001 & $97(77.60)$ & $28(22.40)$ & 0.001 \\
\hline & Female & $77(35.98)$ & $137(64.02)$ & & $114(53.27)$ & $100(46.73)$ & \\
\hline \multirow[t]{3}{*}{ Specialization } & Medical & $53(42.74)$ & $71(57.26)$ & 0.552 & $87(70.16)$ & $37(29.84)$ & 0.006 \\
\hline & Surgical & $71945.51)$ & 85 (54.49) & & 97 (62.18) & $59(37.82)$ & \\
\hline & Others & $22(37.29)$ & $37(62.71)$ & & $27(45.76)$ & $32(54.24)$ & \\
\hline \multirow{2}{*}{$\begin{array}{l}\text { Average number of } \\
\text { patients seen per day }\end{array}$} & $<30$ & $135(43.41)$ & $176(56.59)$ & 0.673 & $195(62.70)$ & $116(37.30)$ & 0.561 \\
\hline & $30+$ & $11(39.29)$ & $17(60.71)$ & & $16(57.14)$ & $12(42.86)$ & \\
\hline \multirow{2}{*}{$\begin{array}{l}\text { Average number of } \\
\text { prescriptions per day }\end{array}$} & $<20$ & $100(42.92)$ & $133(57.08)$ & 0.934 & $137(58.80)$ & $96(41.20)$ & 0.052 \\
\hline & $20+$ & $46(43.40)$ & $60(56.60)$ & & $74(69.81)$ & $32(30.19)$ & \\
\hline \multirow[t]{2}{*}{ Years of experience } & $<16$ & $120(42.86)$ & $160(57.14)$ & 0.864 & $168(60.00)$ & $112(40.00)$ & 0.064 \\
\hline & $16+$ & $26(44.07)$ & $33(55.93)$ & & $43(72.88)$ & $16(27.12)$ & \\
\hline \multirow[t]{4}{*}{ Qualifications } & Specialist & 45 (56.96) & $34(43.04)$ & 0.001 & $62(78.48)$ & $17(21.52)$ & 0.001 \\
\hline & Medical officer & $28(29.47)$ & $67(70.53)$ & & $56(58.95)$ & $39(41.05)$ & \\
\hline & House officer & $39(50.00)$ & $39(50.00)$ & & $51(65.38)$ & 27 (34.62) & \\
\hline & Nurse & $34(39.08)$ & $53(60.92)$ & & $42(48.28)$ & $45(51.72)$ & \\
\hline
\end{tabular}

male participants $(p<0.001)$. Medical officers and nurses showed a higher satisfactory knowledge compared to those with other qualifications $(p<0.001)$. Additionally, female participants had greater desirable practices compared to male participants $(p<$ $0.001)$. Nurses and medical officers also showed higher desirable practices compared to professionals with other qualifications $(p<$ 0.001) (Table 4).

A greater number of male respondents had perceived attitude barriers toward the reporting process than the female respondents $(p<0.001)$. The professionals with surgical and medical specialties had greater perceived attitude barriers than those with other specialties $(p<0.001)$. The participants with less than 16 years of working experience had greater perceived attitude barriers toward ADR reporting than participants with more than 16 years of working experience $(p<0.001)$. House officers and medical officers had greater perceived attitude barriers than specialists and nurses $(p<0.001)$ (Table 5).

Notably, a greater number of female participants had perceived attitude barriers toward reporting card than the male participants $(p=0.002)$. Professionals with medical and surgical specialties had lesser perceived attitude barriers than those with other specialties $(p=0.009)$. Respondents who were consulted by more than 30 patients per day had greater perceived attitude barriers than those who attend less than 30 patients per day $(p<$ 0.001 ). The participants who write more than 20 prescriptions per day had greater perceived attitude barriers toward reporting card than those who write less than 20 prescriptions a day $(p=0.029)$. Nurses had lesser perceived attitude barriers compared to those with other qualifications $(p<0.001)$ (Table 5).

It was also observed that participants who were older than 50 years had greater perceived motivating attitudes toward
ADR reporting compared to those with less than 50 years of age $(p=0.006)$. Those with surgical and other specialties had greater perceived motivating attitudes compared to those with medical specialty $(p=0.015)$ (Table 5).

\section{Factors associated with knowledge, practices, and attitudes with participants' characteristics}

Backward multivariable logistic regression showed that female respondents were 1.86 times more likely to have satisfactory knowledge compared to male respondents $(95 \% \mathrm{CI}$ : $1.105,3.125)$. Medical officers were 4.083 times more likely to have satisfactory knowledge compared to specialists $(95 \% \mathrm{CI}$ : $1.819,9.167)$. Moreover, female respondents were 2.74 times more likely to have desirable practices than male respondents (95\% CI: 1.632, 4.612). Professionals with medical specialty were likely to have 2.68 times lesser desirable practices compared to those with other specialties (95\% CI: 1.358, 5.305).

The professionals from surgical specialty were 3.004 times more likely to have perceived attitude barriers for ADR reporting compared to those from medical specialty $(95 \% \mathrm{CI}$ : $1.056,8.545)$. Professionals with other specialties were likely to have 3.439 times more perceived attitude barriers compared to those with medical specialty $(95 \% \mathrm{CI}: 1.051,11.255)$. Participants who wrote more than 20 prescriptions per day were 2.434 times more likely to have perceived attitudes barriers compared to those who wrote less than 20 prescriptions per day (95\% CI: 1.116, 5.305). It was also noted that participants who attended to more than 30 patients per day were 2.095 times more likely to have perceived motivating attitudes compared to participants who attend less than 30 patients per day $(95 \% \mathrm{CI}$ : $0.912,4.813$ ) (Table 6). 
Table 5. Attitudes toward ADR reporting in relation to socio-demographic factors.

\begin{tabular}{|c|c|c|c|c|c|c|c|c|c|c|}
\hline & & \multicolumn{3}{|c|}{$\begin{array}{l}\text { Perceived barriers toward } \\
\text { reporting process }\end{array}$} & \multicolumn{3}{|c|}{$\begin{array}{l}\text { Perceived barriers toward } \\
\text { reporting card }\end{array}$} & \multicolumn{3}{|c|}{ Perceived motivators } \\
\hline & & No & Yes & $p$ & No & Yes & $p$ & No & Yes & $p$ \\
\hline & & $n(\%)$ & $n(\%)$ & & $n(\%)$ & $n(\%)$ & & $n(\%)$ & $n(\%)$ & \\
\hline \multirow[t]{2}{*}{ Age } & $<50$ & $246(78.85)$ & $66(21.15)$ & \multirow{2}{*}{0.248} & $276(88.46)$ & $36(11.54)$ & \multirow{2}{*}{0.420} & $189(60.58)$ & $123(39.42)$ & \multirow{2}{*}{0.006} \\
\hline & $50+$ & $5(100)$ & $0(0.00)$ & & $5(100.00)$ & $0(0.00)$ & & $0(0.00)$ & $5(100.00)$ & \\
\hline \multirow[t]{2}{*}{ Gender } & Male & $89(71.20)$ & $36(28.80)$ & \multirow{2}{*}{0.001} & $120(96.00)$ & $5(4.00)$ & \multirow{2}{*}{0.002} & $77(61.60)$ & $48(38.40)$ & \multirow{2}{*}{0.509} \\
\hline & Female & $183(85.51)$ & $31(14.49)$ & & $183(85.51)$ & $31(14.49)$ & & $124(57.94)$ & $90(42.06)$ & \\
\hline \multirow[t]{3}{*}{ Specialization } & Medical & $97(78.23)$ & 27 (21.77) & & $119(95.57)$ & $5(4.03)$ & \multirow{3}{*}{0.009} & $86(69.35)$ & $38(30.65)$ & \multirow{3}{*}{0.015} \\
\hline & Surgical & $120(76.92)$ & $36(23.08)$ & 0.022 & $135(86.54)$ & $21(13.46)$ & & $85(54.49)$ & $71(45.51)$ & \\
\hline & Others & $55(93.22)$ & $4(6.78)$ & & $49(83.05)$ & $10(16.95)$ & & $30(50.85)$ & $29(49.15)$ & \\
\hline \multirow{2}{*}{$\begin{array}{l}\text { Average number of } \\
\text { patients seen per day }\end{array}$} & $<30$ & $249(80.06)$ & $62(19.94)$ & \multirow{2}{*}{0.791} & $284(91.32)$ & $27(8.68)$ & \multirow{2}{*}{0.001} & $189(60.77)$ & $122(39.23)$ & \multirow{2}{*}{0.065} \\
\hline & $30+$ & $23(82.14)$ & $5(17.86)$ & & $19(67.86)$ & $9(32.14)$ & & $12(42.86)$ & $16(57.14)$ & \\
\hline \multirow{2}{*}{$\begin{array}{l}\text { Average number of } \\
\text { prescriptions per day }\end{array}$} & $<20$ & $193(82.83)$ & $40(17.17)$ & \multirow{2}{*}{0.075} & $214(91.85)$ & $19(8.15)$ & \multirow{2}{*}{0.029} & $141(60.52)$ & $92(39.48)$ & \multirow{2}{*}{0.497} \\
\hline & $20+$ & $79(74.53)$ & $27(25.47)$ & & $89(83.96)$ & $17(16.04)$ & & $60(56.60)$ & $46(43.40)$ & \\
\hline \multirow[t]{2}{*}{ Years of experience } & $<16$ & $215(76.79)$ & $65(23.21)$ & \multirow{2}{*}{0.001} & $249(88.93)$ & $31(11.07)$ & \multirow{2}{*}{0.556} & $168(60.00)$ & $112(40.00)$ & \multirow{2}{*}{0.563} \\
\hline & $16+$ & $57(96.61)$ & $2(3.39)$ & & $54(91.53)$ & $5(8.47)$ & & $33(55.93)$ & $26(44.07)$ & \\
\hline \multirow[t]{4}{*}{ Qualifications } & Specialist & $70(88.61)$ & $9.00(11.39)$ & & $79(100.00)$ & $100.00(0.00)$ & & $42(53.16)$ & $37(46.84)$ & \\
\hline & Medical officer & $75(78.95)$ & $20.00(21.05)$ & \multirow{3}{*}{0.001} & $88(92.63)$ & $92.63(7.00)$ & \multirow{3}{*}{0.001} & $64(67.37)$ & $31(32.63)$ & \multirow{3}{*}{0.085} \\
\hline & House officer & $51(65.38)$ & $27.00(34.62)$ & & $74(94.87)$ & $94.87(4.00)$ & & $50(64.10)$ & $28(35.90)$ & \\
\hline & Nurse & $76(87.63)$ & $11.00(12.64)$ & & $62(71.26)$ & $71.26(25.00)$ & & $45(51.72)$ & $42(48.28)$ & \\
\hline
\end{tabular}

Table 6. Factors affecting knowledge, practices, and attitude toward ADR reporting.

\begin{tabular}{|c|c|c|c|c|c|c|c|c|c|c|c|}
\hline & \multicolumn{2}{|c|}{ Knowledge } & \multicolumn{3}{|c|}{ Practices } & \multicolumn{3}{|c|}{ Attitudes to barriers } & \multicolumn{3}{|c|}{ Attitudes toward motivators } \\
\hline & $\begin{array}{c}\text { OR } \\
(95 \% \mathrm{CI})\end{array}$ & $p$ & & $\begin{array}{c}\text { OR } \\
(95 \% \mathrm{CI})\end{array}$ & $\bar{p}$ & & $\begin{array}{c}\text { OR } \\
(95 \% \mathrm{CI})\end{array}$ & $\bar{p}$ & & $\begin{array}{c}\text { OR } \\
(95 \% \text { CI })\end{array}$ & $\bar{p}$ \\
\hline Female & $\begin{array}{c}1.859(1.105- \\
3.125)\end{array}$ & 0.020 & Female & $\begin{array}{c}2.744(1.632- \\
4.612)\end{array}$ & 0.000 & Medical & 1 & 0.082 & Medical & 1 & 0.031 \\
\hline $\begin{array}{l}\text { Years of } \\
\text { experience }> \\
16 \text { years }\end{array}$ & $\begin{array}{c}2.303 \\
(0.98-5.411)\end{array}$ & 0.056 & Medical & 1 & 0.018 & Surgical & $\begin{array}{c}3.004(1.056- \\
8.545)\end{array}$ & 0.039 & Surgical & $\begin{array}{c}1.921(1.135- \\
3.261)\end{array}$ & 0.015 \\
\hline Specialists & 1 & 0.003 & Surgical & $\begin{array}{c}1.41(0.832- \\
2.388)\end{array}$ & 0.202 & Others & $\begin{array}{c}3.439 \\
(1.051-11.255)\end{array}$ & 0.041 & Others & $\begin{array}{c}1.999(1.018- \\
3.927)\end{array}$ & 0.044 \\
\hline $\begin{array}{l}\text { Medical } \\
\text { officer }\end{array}$ & $\begin{array}{c}4.083(1.819- \\
9.167)\end{array}$ & 0.001 & Others & $\begin{array}{c}2.684(1.358- \\
5.305)\end{array}$ & 0.005 & $\begin{array}{c}\text { Average number } \\
\text { of prescriptions } \\
\text { per day: }>20\end{array}$ & $\begin{array}{c}2.434(1.116- \\
5.305)\end{array}$ & 0.025 & $\begin{array}{c}\text { Average } \\
\text { number of } \\
\text { patients seen } \\
\text { per day: }>30\end{array}$ & $\begin{array}{c}2.095(0.912- \\
4.813)\end{array}$ & 0.081 \\
\hline Housemen & $\begin{array}{c}1.727 \\
(0.77-3.872)\end{array}$ & 0.185 & & & & & & & & & \\
\hline Nurse & $\begin{array}{c}1.955(0.875- \\
4.369)\end{array}$ & 0.102 & & & & & & & & & \\
\hline
\end{tabular}

Correlation analysis showed that the participants with greater knowledge have greater satisfactory practices $(r=0.169$; $p=0.002)$ and lesser perceived negative attitudes (barriers) $(r$ $=-0.185 ; p=0.001)$. The greater the negative attitude among participants, the higher the unsatisfactory practices $(r=-0.126$; $p=0.020)$, whereas, with greater positive attitudes, practices are more satisfactory $(r=0.172 ; p=0.001)$ (Table 7).

\section{DISCUSSION}

To the best of our knowledge, this is the first study conducted at a tertiary hospital in Malaysia on the KAP toward
ADR reporting among healthcare professionals. Additionally, we determined the association of KAP with demographic factors. The overall response rate was $91.6 \%$ with a greater number of female participants.

According to the Malaysian Pharmacovigilance Guidelines, the main objective of ADR monitoring is to identify previously unrecognized ADRs, recognize factors predisposing to ADRs, measure incidence of ADRs, and compare the drug toxicity in similar therapeutic classes (Sultana et al., 2013). It was evident that more than $85 \%$ of the participants answered the above objectives of ADR reporting correctly except that the statement 
Table 7. Correlation between knowledge, practices, and attitudes toward ADR reporting.

\begin{tabular}{llcc}
\hline Variable 1 & Variable 2 & $\boldsymbol{r}$ & $\boldsymbol{p}$ \\
\hline Knowledge & Practices & $0.169^{* *}$ & 0.002 \\
Knowledge & Perceived attitudes toward barriers & $-0.185^{*}$ & 0.001 \\
Practices & Perceived attitudes toward barriers & $-0.126^{*}$ & 0.020 \\
Practices & Perceived positive attitudes toward motivators & $0.172^{* *}$ & 0.001 \\
\hline
\end{tabular}

"ADR reporting helps to compare the drug toxicity in similar therapeutic classes" obtained correct response from less than onethird of the participant. Overall, in our study, $56.9 \%$ of respondents showed satisfactory knowledge about the purpose of ADR reporting. In an earlier study, $42.8 \%$ of the private practitioners in Klang Valley, Malaysia, showed satisfactory knowledge (Agarwal et al., 2013). Other studies have also reported that a significant proportion of medical practitioners have inadequate knowledge about ADRs and pharmacovigilance (Chopra et al., 2011; Ergün et al., 2019; Li et al., 2004; Lopez-Gonzalez et al., 2009). Although a greater knowledge regarding the type and purpose of ADR reporting was observed among participants in the current study compared to that among private practitioners in an earlier study, a much higher knowledge is desirable considering the availability of resources at a tertiary healthcare center. Among the factors associated with knowledge, female respondents showed greater satisfactory knowledge compared to male respondents ( $p$ $<0.001)$. A previous study showed gender-related differences in ADR reporting in The Netherland; however, the causes of these differences remain uncertain (De Vries et al., 2019). We also observed that medical officers have greater satisfactory knowledge compared to specialists $(p<0.001)$, which might be attributed to their greater engagement in patient care. Similar observations were made by some researchers (Gupta and Udupa, 2011; Gurmesa and Dedefo, 2016; Kunnoor and Lohit, 2017; Palaian et al., 2011) but not by others (Abdel-Latif \& Abdel-Wahab, 2015; Aziz et al., 2007; Fadare et al., 2011; Punj \& Hakeem, 2020).

Notably, the current study showed that $71.98 \%$ of the respondents suspected ADR but did not report it. This response rate was lower compared to $94.74 \%$ among private practitioners in Klang Valley as reported earlier (Agarwal et al., 2013). The response by more than half of the participants $(56 \%)$ in this study that they will report ADR only if the reaction is proven and only if they were confident that the reaction is an ADR shows their uncertainty about ADR reporting. In a previous study, uncertainty, negligence, work-related factors, heavy workload, and lack of time were found to contribute to unsatisfactory practices (Li et al., 2004). Interestingly, despite more than half of the participants showing satisfactory knowledge, nearly three-fourth of them showed unsatisfactory practices. We observed that, compared to medical and surgical specialists, others were more likely to report ADRs, which may perhaps be attributed to greater familiarity of some specialists such as anesthesiologists with ADRs, which constituted the majority of the "others" category in the current study. Similar observations have been reported by some researchers (Bäckström et al., 2000; Dorji et al., 2016; Haines et al., 2020) but not by others (Aziz et al., 2007; Herdeiro et al., 2005). We also observed that female respondents were more likely to have desirable practices compared to male respondents. This may be attributed to greater ADR-related knowledge among females as well as their greater caring attitude. Derose et al. (2001) have earlier reported that patients preferred female medical professionals due to their trustworthy and caring attitude.

We considered widely reported Inman's criteria to understand the impact of participant's attitudes toward ADR reporting (Inman, 1996). As described earlier, seven attitudinal attributes, complacency, fear and guilt, diffidence, indifference, lethargy, ignorance, and financial incentives, were considered (Agarwal et al., 2013; Inman, 1996). In the current study, more than $85 \%$ of the participants showed complacency because they believed that ADRs are detected by postmarketing surveillance and only safe drugs are marketed. Additionally, 34\% of respondents showed ignorance as they responded that only serious or unusual reactions should be reported. We also observed the expression of fear and guilt among participants as at least $56 \%$ of them were concerned that ADR may trigger investigation into legal liabilities, and they may be held responsible for doing harm to the patient. A large proportion of participants showed lethargy toward ADR reporting as they were unsure of the address (78.2\%), availability of reporting cards (45\%), the relevant phone numbers $(77.0 \%)$, and considered ADR reporting time-consuming (55.2\%). We observed that only $21.5 \%$ of respondents showed diffidence, which refers to appearing foolish by reporting ADRs. Less than one-fourth of the participants showed indifference toward contributing to new knowledge by reporting ADRs. Only around 27.4\% of the participants expected financial incentives for ADR reporting as they regarded it as their professional obligations.

Interestingly, we observed that respondents writing more than 20 prescriptions per day were less likely to report ADR compared to those writing less than 20 prescriptions a day [AOR: $2.434(95 \% \mathrm{CI} ; 1.116,5.305 ; p=0.025)]$. This may be attributed to their workload. The finding that professionals from surgical and other specialties were three times [AOR: $3.004(95 \%$ $\mathrm{CI} ; 1.056,8.545 ; p=0.039)]$ more likely to have barriers toward ADR reporting compared to those from medical specialty could be attributed to the fact that the professionals from surgical branches focus on operative procedures and may lack in-depth knowledge of the pharmacological actions of drugs. However, professionals from surgical and other specialties were two times [AOR: $1.921(95 \%$ CI; $1.135,3.261 ; p=0.015)]$ more likely to perceive motivators of ADR reporting. We also observed that medical officers were more likely to report ADRs than others [AOR: 2.684 (95\% CI; 1.358, 5.311; $p=0.005)$ ] which could be because medical officers are the ones who spend relatively longer time for patient care.

The findings that there was a positive correlation between knowledge and practice $(r=0.169 ; p=0.002)$ is plausible and may be attributed to the fact that better understanding of the necessity of pharmacovigilance and the process of reporting would yield favorable practice. It was reported that practice is positively related to knowledge (Dowell, 1969). 
On the other hand, attitude, which represents a mental status toward an external stimulus, was found to affect practices negatively $(r=-0.126 ; p=0.020)$. A negative attitude, without argument, would reflect undesirability or low preference for the intended action.

\section{CONCLUSION}

The findings of the present study showed that the healthcare professionals working at a tertiary healthcare center had satisfactory knowledge but showed poor practices due to perceived barriers toward ADR reporting card and reporting processes. Since we observed that professionals with greater knowledge have lesser perceived negative attitudes and greater satisfactory practices and that the greater positive attitudes promote satisfactory practices, it is important that robust educational intervention and training is designed to enhance the ADR reporting in Malaysia.

\section{ACKNOWLEDGMENTS}

The authors would like to acknowledge the International Medical University, Malaysia, and Hospital Tuanku Ja'afar, Seremban, Malaysia, for supporting them in conducting this study. The authors would like to thank the Director-General of Health, Malaysia, for the permission to publish this study.

\section{AUTHOR CONTRIBUTIONS}

All authors made substantial contributions to conception and design, acquisition of data, or analysis and interpretation of data; took part in drafting the article or revising it critically for important intellectual content; agreed to submit to the current journal; gave final approval of the version to be published; and agree to be accountable for all aspects of the work. All the authors are eligible to be an author as per the international committee of medical journal editors (ICMJE) requirements/guidelines.

\section{CONFLICTS OF INTEREST}

The authors declare that they have no conflicts of interest

\section{FUNDING}

This study was supported by a grant from the International Medical University with a grant number BMS1/2020(6).

\section{PUBLISHER'S NOTE}

This journal remains neutral with regard to jurisdictional claims in published institutional affiliation.

\section{REFERENCES}

Abdel-Latif MM, Abdel-Wahab BA. Knowledge and awareness of adverse drug reactions and pharmacovigilance practices among healthcare professionals in Al-Madinah Al-Munawwarah, Kingdom of Saudi Arabia. Saudi Pharm J, 2015; 23(2):154-61

Agarwal R, Daher AM, Ismail NM. Knowledge, practices and attitudes towards adverse drug reaction reporting by private practitioners from Klang Valley in Malaysia. Malays J Med Sci, 2013; 20(2):52.

Aronson JK, Ferner RE. Clarification of terminology in drug safety. Drug Saf, 2005; 28(10):851-70.

Aziz Z, Siang TC, Badarudin NS. Reporting of adverse drug reactions: predictors of under-reporting in Malaysia. Pharmacoepidemiol Drug Saf, 2007; 16(2):223-8.

Bäckström M, Mjörndal T, Dahlqvist R, Nordkvist-Olsson T Attitudes to reporting adverse drug reactions in northern Sweden. Eur J Clin Pharmacol, 2000; 56(9):729-32.
Chopra D, Wardhan N, Rehan H. Knowledge, attitude and practices associated with adverse drug reaction reporting amongst doctors in a teaching hospital. Int J Risk Saf Med, 2011; 23(4):227-32.

Daher AM, Amin F. Assessing the perceptions of a biostatistics and epidemiology module: views of year 2 medical students from a Malaysian University. A cross-sectional survey. BMC Med Educ, 2010; 10(1):1-9.

De Vries ST, Denig P, Ekhart C, Burgers JS, Kleefstra N, Mol PG, van Puijenbroek EP. Sex differences in adverse drug reactions reported to the National Pharmacovigilance Centre in the Netherlands: an explorative observational study. Br J Clin Pharmacol, 2019; 85(7):1507-15.

Derose KP, Hays RD, McCaffrey DF, Bakerg DW. Does physician gender affect satisfaction of men and women visiting the emergency department? J Gen Intern Med, 2001; 16(4):218-26.

Dorji C, Tragulpiankit P, Riewpaiboon A, Tobgay T. Knowledge of adverse drug reaction reporting among healthcare professionals in Bhutan: a cross-sectional survey. Drug Saf, 2016; 39(12):1239-50.

Dowell LJ. The relationship between knowledge and practice. J Educ Res, 1969; 62(5):201-5.

Elkalmi RM, Hassali MA, Ibrahim MIM, Liau SY, Awaisu A. A qualitative study exploring barriers and facilitators for reporting of adverse drug reactions (ADRs) among community pharmacists in Malaysia. J Pharm Health Serv Res, 2011; 2(2):71-8.

Ergün Y, Ergün TB, Toker E, Ünal E, Akben M. Knowledge attitude and practice of Turkish health professionals towards pharmacovigilance in a university hospital. Int Health, 2019; 11(3):177-84.

Fadare, J. O., Enwere, O. O., Afolabi, A., Chedi, B., \& Musa, A Knowledge, attitude and practice of adverse drug reaction reporting among healthcare workers in a tertiary centre in Northern Nigeria. Tropical Journal of Pharmaceutical Research, 2011; 10(3):235-42.

Gupta P, Udupa A. Adverse drug reaction reporting and pharmacovigilance: knowledge, attitudes and perceptions amongst resident doctors. J Pharm Sci Res, 2011; 3(2):1064.

Gurmesa LT, Dedefo MG. Factors affecting adverse drug reaction reporting of healthcare professionals and their knowledge, attitude, and practice towards ADR reporting in Nekemte Town, West Ethiopia Biomed Res Int, 2016; 2016:5728462.

Haines H, Meyer J, Summers R, Godman B. Knowledge, attitudes and practices of health care professionals towards adverse drug reaction reporting in public sector primary health care facilities in a South African district. Eur J Clin Pharmacol, 2020; 76(7):991-1001.

Hazell L, Shakir S. Under-reporting of adverse drug reactions: a systematic review. Drug Saf, 2006; 29(5):385-96.

Herdeiro MT, Figueiras A, Polónia J, Gestal-Otero JJ Physicians' attitudes and adverse drug reaction reporting. Drug Saf, 2005; 28(9):825-33

Howard RL, Avery AJ, Slavenburg S, Royal S, Pipe G, Lucassen P, Pirmohamed, M. Which drugs cause preventable admissions to hospital? A systematic review. Br J Clin Pharmacol, 2007; 63(2):136-47.

Inman, $\mathrm{W}$. Attitudes to adverse drug reaction reporting. Br J Clin Pharmacol, 1996; 41(5):434-5.

Kunnoor N, Lohit K. Perception of doctors towards adverse drug reaction (ADR) reporting: a cross sectional survey using a validated questionnaire. Int J Basic Clin Pharmacol, 2017; 6:2671-5.

Li Q, Zhang SM, Chen HT, Fang SP, Yu X, Liu D, Shi LY, Zeng FD. Awareness and attitudes of healthcare professionals in Wuhan, China to the reporting of adverse drug reactions. Chin Med J, 2004; 117(6):856-61.

Lopez-Gonzalez E, Herdeiro MT, Figueiras A. Determinants of under-reporting of adverse drug reactions. Drug Saf, 2009; 32(1):19-31.

National Pharmaceutical Regulatory Agency. (2020). MADRAC bulletin: adverse event report for 2019. Available via https://www.npra.gov. my/easyarticles/images/users/1108/MADRAC\%20Bulletin/MADRACBulletin-01-2020.pdf

Palaian S, Ibrahim MI, Mishra P. Health professionals knowledge, attitude and practices towards pharmacovigilance in Nepal. Pharm Pract, 2011; 9(4), 228. 
Punj V, Hakeem M. Assessment of knowledge and reporting of adverse drug reaction in resident doctors in a teaching hospital in North India. Int J Basic Clin Pharmacol, 2020; 9(2):233-41.

Sultana J, Cutroneo P, Trifirò G. Clinical and economic burden of adverse drug reactions. J Pharmacol Pharmacother, 2013; 4(Supp11):S73.

Wise L, Parkinson J, Raine J, Breckenridge, A. (2009). New approaches to drug safety: a pharmacovigilance tool kit. Nat Rev Drug Discov, 2009; 8(10):779-82.

World Health Organization. (2020). The importance of pharmacovigilance. Available via https://apps.who.int/iris/bitstream/ handle/10665/42493/a75646.pdf

\section{How to cite this article:}

Burud I, Daher AM, Din HB, Agarwal P, Zakaria J, Agarwal R. Knowledge, attitudes, and practices related to adverse drug reaction reporting by healthcare professionals in a tertiary hospital in Malaysia. J Appl Pharm Sci, 2021; 11(10): 079-087. 